\title{
Industrie 4.0 and a sustainable development: a short study on the perception and expectations of experts in Germany
}

\author{
Silke Niehoff* and Grischa Beier \\ Institute for Advanced Sustainability Studies e.V., \\ Berliner Strasse 130, \\ Potsdam, 14467, Germany \\ Email: Silke.Niehoff@iass-potsdam.de \\ Email: Grischa.Beier@iass-potsdam.de \\ ${ }^{*}$ Corresponding author
}

\begin{abstract}
Trends are predicting a further 'industrial revolution' based on digitalisation. The industry has always had an influence on the sustainable development and it, therefore, seems essential to better understand and monitor the transformations in the industry from a sustainability science perspective. This short study intends to provide a starting point for research focused specifically on the environmental dimension of the triple bottom line. Based on a survey conducted among 100 participants from companies and research institutions and complemented by two semi-structured interviews, this study provides the first set of ideas and insights. Our results suggest that digitalisation has the potential to positively affect the environmental dimension of a sustainable development. However, the overall sustainability of digitalised industry has to receive more attention from researchers as well as from companies, in order to better understand and quantify this potential, and avoid a mere problem shifting as well as rebound effects.
\end{abstract}

Keywords: sustainable development; digitalisation; resource efficiency; renewable energies; environmental management.

Reference to this paper should be made as follows: Niehoff, S. and Beier, G. (2018) 'Industrie 4.0 and a sustainable development: a short study on the perception and expectations of experts in Germany', Int. J. Innovation and Sustainable Development, Vol. 12, No. 3, pp.360-374.

Biographical notes: Silke Niehoff holds a Diploma in Environmental Management. She is currently working for IASS Potsdam as Research Associate. Her research interests include digitalisation and its possible influence on the sustainable management of companies.

Grischa Beier holds a $\mathrm{PhD}$ in Engineering. He is currently working for IASS Potsdam as Scientific Project Leader. His research interests include digitalisation (especially with regard to industrial processes) and its impacts on sustainability.

Copyright (C) The Authors(s) 2017. Published by Inderscience Publishers Ltd. This is an Open Access Article distributed under the CC BY license. (http://creativecommons.org/licenses/by/4.0/) 


\section{Introduction}

Industrial production is currently undergoing a process of fundamental transformation: after mechanisation, electrification, and the advent of information and communication technology (ICT), trends are now predicting a further 'industrial revolution' based on digitalisation, where smart and interconnected objects organise themselves in the production process (Herrmann et al., 2014; Kagermann et al., 2013). The vision behind this prediction lies in the convergence of the physical world of industrial production and the digital world of information technology - in other words, the creation of a digitalised and interconnected industrial production (Herrmann et al., 2014; Kagermann et al., 2013; Kang et al., 2016; Schmidt et al., 2015). This vision has entered into public debate under different names in different regions: in Germany, where it first emerged, it is commonly referred to and promoted under the title 'Industrie 4.0', whereas in the US, it is known as the Industrial Internet (of Things).

Regardless of the term, the idea behind this technological vision could transform entire value chains. It would allow producing goods according to increasingly individualised customer requirements, while production processes would use the digitally available data - thanks to the interconnectedness of all entities involved in value creation - to determine the optimal value creation flow at any time (Kang et al., 2016; Schmidt et al., 2015). These connections between people, elements of manufactured products, and manufacturing systems themselves, could give rise to new value creation networks that are dynamic, self-organising, and expand beyond the borders of the company.

Since this could deeply transform industrial production, and as the industry has always played an important role in finding pathways to sustainable development, it is essential to also monitor the related transformations in the industry from a sustainability science perspective. With respect to the triple bottom line approach, industry influences all three dimensions, as different indicators show. An example of the influence on the economic dimension is provided by the gross value added indicator (GVA). In Germany, industry accounts for $25.5 \%$ of the GVA (Eurostat, 2016). Almost a fifth (18.8\%) of employees in Germany work in the industrial sector (Eurostat, 2015c), exemplifying the importance of industry not only in the economic but also in the social dimension. But industrial activities are also one of the most significant sources of environmental impacts. The industrial sector in Germany accounts for $28.0 \%$ of the final energy consumption (Eurostat, 2015a) while being responsible for $19.2 \%$ of all greenhouse gas emissions (Eurostat, 2015b).

This paper approaches the potential impacts of Industrie 4.0 on sustainable development through an empirical survey, asking manufacturing companies from different sectors and research institutions in Germany. These findings are complemented by two semi-structured qualitative interviews, in which we have discussed details of the study with two experts from the industry to improve our understanding of some of the findings. Both experts were asked questions from the questionnaire with additional in-depth questions focusing on their respective field of expertise. In this paper, the focus is on the potential environmental effects of Industrie 4.0. At the beginning of this paper a state-of-the-art analysis is presented giving a brief overview of existing research findings, and addressing especially the industry-relevant environmental aspects, and how they might be impacted by the digitalisation of production processes. Following this section, the method used to design and conduct the survey is described. In Section 4 the results of 
the survey are presented, followed by a discussion of the key findings, using a short scenario. The paper concludes with an outlook for future research.

\section{State-of-the-art}

Since the concept of Industrie 4.0 (the digitalised and interconnected industry) is rather new (Kagermann et al., 2013), research has largely focused so far on sustainability issues in 'conventional' manufacturing systems which are less subject to digitalisation and interconnectedness. Some research findings, however, already address implicitly sustainability indicators and how they will potentially be affected by the comprehensive digitalisation of industrial production processes. These studies are primarily focused on the social dimension, including changes in industrial work life (e.g., Autor and Dorn, 2013; Bowles, 2014; OECD, 2014) as well as technological and economic developments in the context of the Industrial Internet (e.g., Derler et al., 2012; Federal Ministry for Economic, 2015; Lee et al., 2015). On a more general level, Keeso examines possible links between big data and environmental sustainability in different organisations such as environmental NGOs, governments or companies. Keeso concludes that corporate social responsibility efforts could particularly benefit from big data availability, especially through improved performance measurement, and a resulting "[...] sense of ownership of sustainability initiatives" (Keeso, 2014, p.26).

However, considerably less research has been dedicated to investigating potentials for resource efficiency, or a hypothetical symbiosis of a digitalised industry with renewable energies (UNIDO, 2017). Expectations for improved resource efficiency through digitalisation remain nevertheless high, albeit not based on fundamental research yet. Geissbauer claims an improvement of resource efficiency up to $20 \%$ is possible in the next five years (Geissbauer et al., 2014), while Rogers speaks of "annual energy cost savings of intelligent efficiency technologies for the commercial and manufacturing sectors that could exceed $\$ 50$ billion" (Rogers et al., 2013, p.v). But there are also critical voices pointing to possible trade-offs between the resource consumption and the resource efficiency of a digitalised production (Kagermann et al., 2013; Beier et al., 2015). Rebound effects still have to be evaluated to assess the saving potential of new technologies, but especially in the case of ICT. Only a few studies have addressed this topic so far (Gossart, 2015).

In the conventional technological context, approaches to optimise resource efficiency in producing companies are not new to research, and can be addressed on various levels (Duflou et al., 2012). Increased resource efficiency can indeed be achieved through technological improvements at the machine tool level (Brecher et al., 2010), or on a larger scale through the restructuring of manufacturing sequences ( $\mathrm{Gu}$ et al., 2013) and factory layouts as well as entire value creation networks in the case of globally operating enterprises (Duflou et al., 2012). A comprehensive review of these resource-efficient technologies and strategies is presented in Rohn et al. (2014).

Ding et al. (2017) pursue a more customer-oriented approach that opens up opportunities for a digitalised industry by introducing an algorithmic description for a resource service scheduling problem in the context of industrial product-service systems, that helps reduce the overall resource consumption. The paper of Krückhans and Meier (2013) introduces a framework that enables the retrofit of older manufacturing systems, by identifying resource efficient operating points and representing them through real and 
virtual automation elements. Another approach for a more sustainable production process is the integration of sustainability metrics and indicators into existing manufacturing systems, as shown by Larreina who developed a demo approach of a smart manufacturing execution system (SMES) which integrates sustainability aspects like energy efficiency (Larreina et al., 2013). Based on a conventional MES, it is enhanced through new hardware architecture to directly collect, analyse and optimise information on resource consumption from the machines using sustainability metrics, as described in e.g., ISO14955 (environmental evaluation of machine tools).

Cyber physical energy systems (CPES) allow steering digitalised industrial processes, and therefore potentially support their temporal flexibility. According to Bornschlegl et al. (2013) energy efficiency could be increased through the use of cyber-physical systems by reducing the base load, especially during unproductive periods in the production flow, and by selectively switching off temporarily unnecessary components.

The majority of these studies focus on specific aspects or indicators of the triple bottom line approach, but without explicitly making a relation to the overarching aims of a 'sustainable development'. The study presented in this paper aims at partially addressing this research gap, by providing a better understanding of possible environmental aspects of Industrie 4.0 in Germany.

\section{Study design}

The survey was conducted with the help of an online questionnaire created with the tool LimeSurvey. The questionnaire was piloted twice with two colleagues, who have a broad experience with questionnaires but were not familiar with the general topic addressed in this survey. Their feedback was used to improve the quality, structure and clarity of the questionnaire. The questionnaire started with a text explaining all relevant terms used in the following questions. The invitation to participate in the survey was distributed by email and published in selected newsletters from German engineering organisations such as the VDI or ProSTEP iViP. The survey addressed individuals employed both in the engineering sector and in engineering science, and who had already dealt with the issues relating to Industrie 4.0 in their professional roles. In total, 102 people participated in the survey. Most participants work in the branches automotive $(20 \%)$, information and communication technologies $(20 \%)$, machine and plant engineering $(18 \%)$, or aerospace $(10 \%)$. They have very different roles in their organisations, the most frequent ones being development (37 participants), services (16), management (13) and research (9). 42 of the participants work in companies with more than 5000 employees, 16 people in companies with fewer than 5000 but more than 250 employees, while the rest of the participants works in companies with fewer than 250 employees. Participants were not obliged to answer all of the questions, but were encouraged to leave blank those questions which they did not feel competent to answer. This is why the total amount of given answers $(\mathrm{N})$ varies across questions. The questionnaire ${ }^{1}$ contained two main thematic blocks: the future of work in production, and the future of production itself.

The results of the quantitative survey were complemented by two semi-structured interviews. The aim of the interviews was not to conduct a full qualitative study, but rather to discuss details of the study with two experts from the industry to improve our understanding of some of the findings. Questions addressed the general vision of a digitalised industry, the future of work, resource and energy efficiency in the context of 
Industrie 4.0, as well as the future of energy supply with additional in-depth questions focusing on their respective field of expertise. From all volunteering candidates, the two interviewees were chosen as they seemed most suitable regarding the compatibility of their work background with the topics of the survey. They work for companies with more than 100,000 employees, which was a criterion in the selection process, as studies show, that big companies are the frontrunners in implementing Industrie 4.0 (e.g., Glatz, 2016; IDG Research Services, 2017). Interviewee one (I1) works in the middle management in the automotive branch, and was asked because of his experience in environmental management, while interviewee two (I2) is a high-level manager in the manufacturing industry, and was chosen because of his expertise regarding possible future technical developments. Information retrieved from the two qualitative interviews was used to complement the results of the survey, where suitable. The related statements were then anonymised and marked in the text with either I1 or I2.

This paper is focused on the potential environmental effects of Industrie 4.0. The German Sustainability Strategy and its indicators were used as a reference point, to extract relevant environmental indicators. The German Sustainability Strategy was chosen as a reference point, as it was developed integrating multiple stakeholders (results being based on five conferences including the national, federal and local governments, NGOs and other members of the public) and is therefore recognised and widely accepted in the German sustainability community. The strategy contains 63 key indicators and quantified targets, allowing for the "[...] tracking of successes and failures in the attainment of the Strategy's goals [...]" and therefore serving "[...] as a basis for the management of sustainable policies and necessary realignments, but also as a transparent source of information for democratic decision-making and debate" (The Federal Government, 2017, p.4). These key indicators were compared with the expected sustainability improvements of a digitalised industry as they are frequently expressed in different (often non-scientific) publications (e.g., Kagermann et al., 2012; Bundesministerium für Bildung und Forschung, 2013; Geissbauer et al., 2014; Statistisches Bundesamt, 2014) in order to validate these claims. On this basis, it was decided to select the indicators of resource efficiency (including energy efficiency and material efficiency) and overall energy consumption as well as renewable energy sources - representative of the energy transition - as main indicators of the study. The conduct of the study does not allow for quantitative predictions, but provides the first set of suggestions on the environmental challenges and opportunities for a sustainable industrial development in the context of Industrie 4.0.

\section{Results of the study}

In the following section, a selection of the results from the survey and the two interviews is presented. Before taking a look at the chosen environmental indicators, some general results concerning the familiarity of the participants with the concept of Industry 4.0 are presented, and the general expectations of how and to what extent the transformation will take place. This provides an important basis when assessing possible influences of Industrie 4.0 on the environmental dimension of sustainability. 


\subsection{Future production and sustainability}

In order to have a better understanding of how participants picture the concept of a digitalised industry in practice, they were questioned about their familiarity with the term Industrie 4.0, and their vision for the future as well as the influence of Industrie 4.0 on their companies.

Twenty-nine percent of the participants stated that they are 'very familiar', and $42 \%$ that they are 'familiar' with the concept of Industrie 4.0. 27\% of the participants felt less experienced with the concept, but only $2 \%$ had no knowledge at all of Industrie 4.0 (population $(N)=100$ ). The majority of the participants characterised the influence of Industrie 4.0 on their companies as 'very big' or 'big' $(66.7 \%, N=69)$. From a time perspective, the implementation of digitalised production processes is anticipated within the next decade (I2). From a context perspective, the transformation is expected to happen successively to large investments, for example in new production lines (I1).

The next thematic block in the survey addressed the future of production and the major changes expected. Important elements of Industrie 4.0 are the digital interconnectedness of machines and product components, and their intelligence - in particular, their ability to communicate with each other.

The participants were asked to gauge the extent to which they expect production facilities to be interconnected in the future; a) within their company, and b) with external means of production. The survey showed that $63.4 \%(N=71)$ of the participants expected production means to display a considerably greater degree of interconnectedness within their companies, while $35.2 \%$ forecasted a slight increase (see Figure 1). The picture is however different when it comes to the expected degree of interconnectedness with external means of production: only $39.4 \%$ of the participants assumed a considerable increase of external interconnectedness, and $23.9 \%$ a slight increase. At the same time, $22.5 \%(N=71)$ of the participants expected that individual product components will be delivered much more often - and $49.3 \%$ more often - from specialised suppliers than today.

Figure 1 Expected interconnectedness within the company, and external (see online version for colours)

\section{Question: internal/external Interconnectedness}

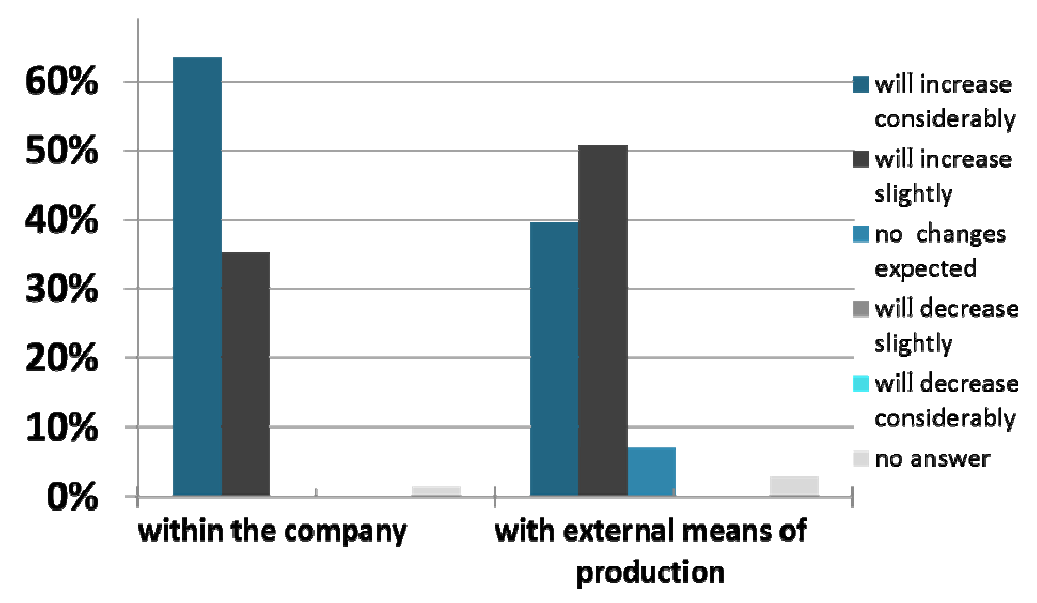


It was then tried to assess, if a connection is already established between sustainability policies in companies and the vision of a digitalised production. As shown in Figures 2, $57.1 \%$ of the participating companies $(N=70)$ have a sustainability strategy and/or even operate an environmental management system (EMS). Of all companies with such a strategy and/or an EMS, 21 participants (53.9\%) agreed that Industrie 4.0 will have an impact on this strategy and/or on the EMS, whereas 12 participants (30.8\%) foresee no influence $(N=39)$.

Figure 2 Companies with a sustainability strategy or EMS and the expected influence on this strategy/EMS in the context of Industrie 4.0 (see online version for colours)

Question: Sustainability strategy

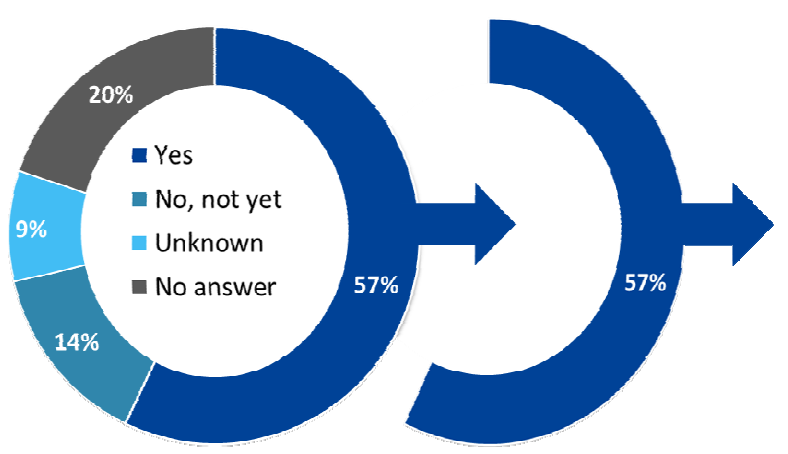

Question: Influence on strategy by digitalization

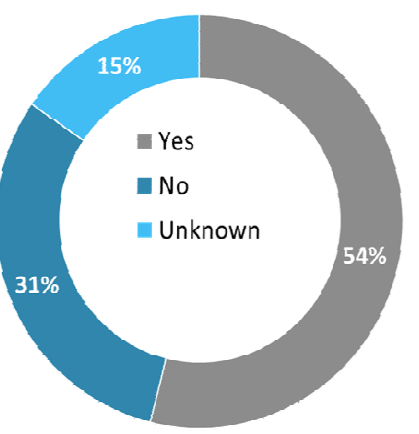

\subsection{Potential effects on resource efficiency}

Industrie 4.0 is seen as an instrument with the potential to improve the environmental footprint of industrial production, especially by better controlling manufacturing processes (I1). Resource efficiency is expected to be a major aspect of this improvement, with $53.5 \%$ of the participants $(N=71)$ seeing resource efficiency as a very important factor - and $38.0 \%$ as an important factor - in strategic decision-making in the future (see Figure 3). Improving resource efficiency is seen as about equally as important for energy ( $38.5 \%, N=169$, multiple answers allowed) as for materials $(32.5 \%)$.

Generally, our interviewed experts assumed the biggest potential for more resource efficiency through the prevention of overproduction resulting from a demand-driven production in 'real time' (I1), a more time-efficient production (I2), and optimised logistics (I1).

Initiatives to increase energy efficiency are already being implemented; as both interviewees stated that their companies have energy efficiency targets for production (I1/I2) as well as for the use phase of their products (I1). Regarding material efficiency in the automotive branch, re-use is a central topic (I1). Additional concerns related to an improved material efficiency and reduced material consumption include the substitution of 'critical raw materials' (for example rare earth elements) and the increased use of secondary raw materials (I1).

Unsurprisingly the majority of participants expect that the proportion of IT in the total product will increase considerably, in the product 'interior' $(62.9 \%, N=70)$, as well as for the user interface $(67.6 \%, N=71)$. When it comes to the individualisation of products - ranging from mass-produced products, over the individualisation of 
features, to completely customer-specific products - most participants assume that the proportion of customer-designed features will increase significantly $(41.4 \%, N=87)$. Both aspects, the increased use of IT components as well as the individualisation of products might have an effect on resource efficiency as will be discussed later in the paper (see Section 4.4).

Figure 3 Importance of resource efficiency in future strategic decision-making (see online version for colours)

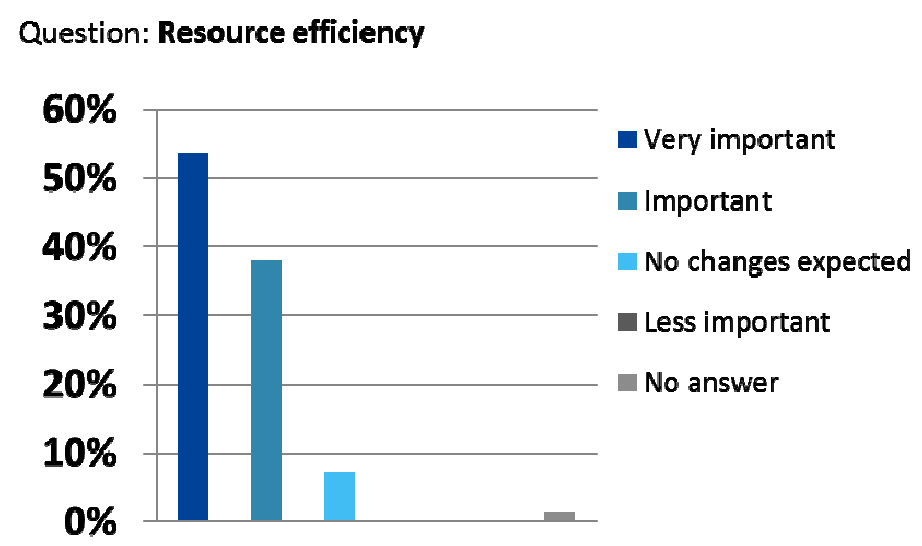

\subsection{Potential effects on energy consumption and renewable energy sources}

One major thematic block of our survey addressed energy-related questions. When asked about how much they expect the energy consumption in their respective companies to change in the context of Industrie 4.0, there were only small variations between the three categories of energy: thermal $(N=67)$, electrical $(N=69)$ and chemical $(N=67)$ energy. For thermal and chemical energy, hardly did any participant foresee significant changes: $41.8 \%$ expected thermal energy consumption not to change at all, while $10.5 \%$ expect a slight increase, and twice as many expected a slight decrease. Regarding the chemical energy consumption, $37.3 \%$ foresaw no changes due to the digitalisation of industrial processes, while $13.4 \%$ considered their company would consume slightly more chemical energy - three times as many as those who anticipated a slight decrease. Only for the category of electrical energy consumption did the majority of our participants anticipate changes due to Industrie 4.0: a combined $34.8 \%$ expected a major or slight increase while only $23.2 \%$ foresaw a major or slight decrease of energy consumption (see Figure 4 ).

When asked about the potential plans of these companies to produce their own renewable energy in the future $(N=69), 31.9 \%$ confirmed - and $27.5 \%$ denied - such plans, while $13 \%$ did not know whether their company had such plans. The remaining $27.6 \%$ of the participants chose not to answer the question (see Figure 5). Both interviews confirmed the importance of the subject of renewable energy production, one company having already its own renewable energy sources or test-environments in place (I1), and the other company thinking about solutions, especially to balance the fluctuations of renewable energy production (I2).

These fluctuations could potentially be used by a digitalised industry, since one of the promising effects of digitising manufacturing processes is their improved temporal 
flexibility. Theoretically, this would enable companies to e.g., execute their energyintensive manufacturing processes when there is an energy surplus in the market, and thus reduce the energy-related costs of these processes. Figure 6 shows that $11.6 \%$ of the participants claimed that their company would adapt production processes accordingly on a bigger scale, and another $29 \%$ at least on a smaller scale. $21.7 \%$ were rather sceptical about their company taking advantage of this potential benefit, while $10.1 \%$ did not see any chance for this to happen. Both interviewees saw a potential for flexibilisation, but at the same time both pointed out that the energy forecast is still a critical factor. One expert said his company was already evaluating opportunities to take advantage of this flexibility, but also pointed out that the overall capacity which could potentially be flexibly switched is mostly limited to certain non-energy-intensive processes (I2).

Figure 4 Expected energy consumption in the future (see online version for colours)

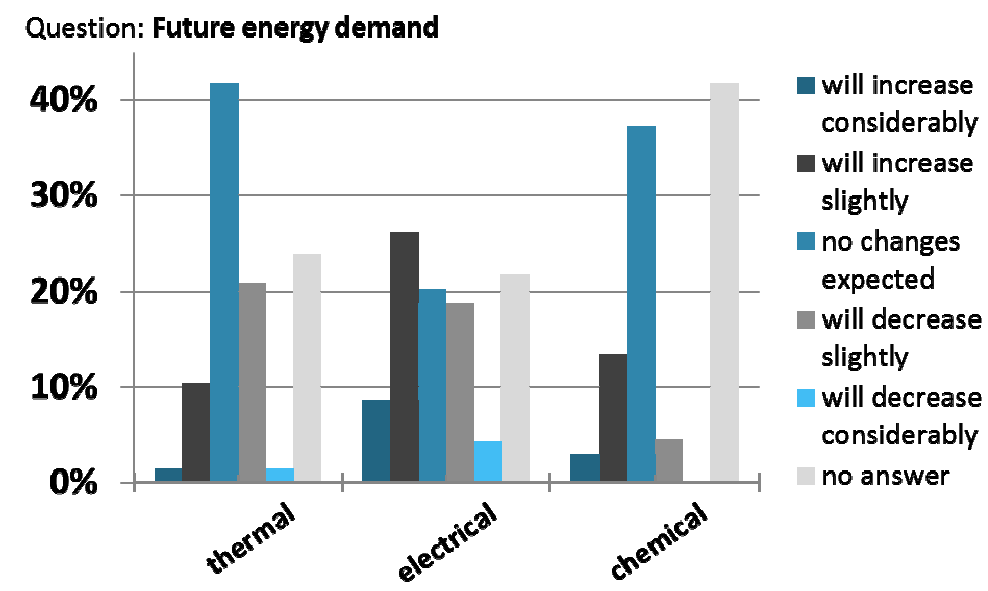

Figure 5 Future plans of renewable energy production (see online version for colours)

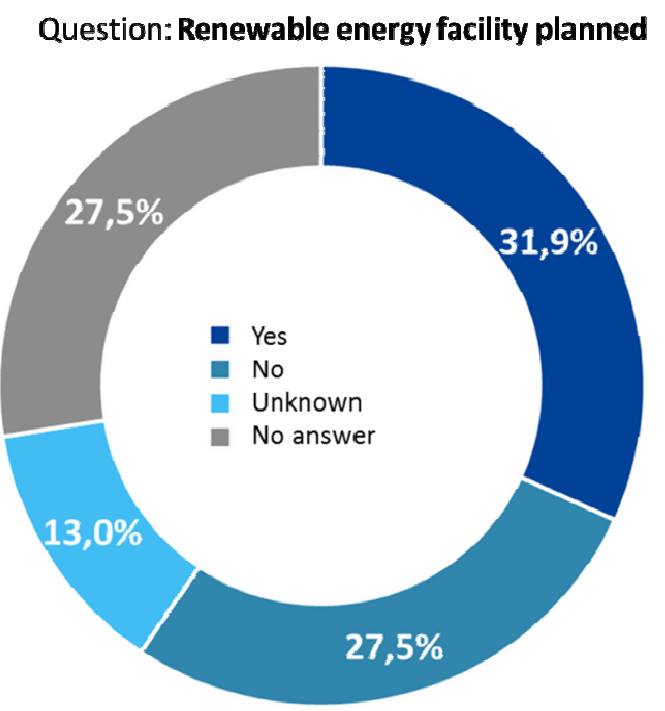


Figure 6 Adapt production to energy fluctuation (see online version for colours)

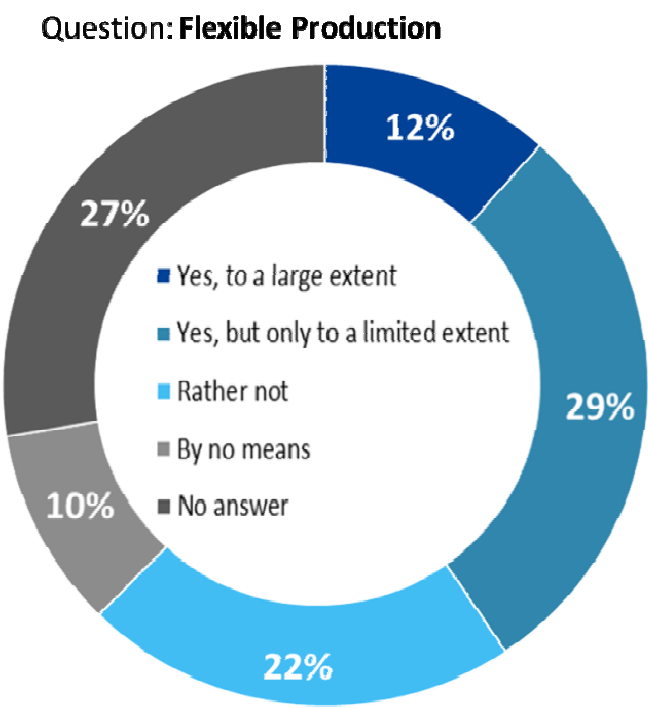

In summary, it can be said that no major changes regarding the energy consumption were expected by the participants of the survey. If at all, there was a small tendency for slightly increased electrical energy and slightly decreased thermal energy consumption. On the other hand, a relatively big share of the companies has plans to produce their own renewable energy in the future, or to flexibly shift its processes to benefit from cheaper energy prices.

\section{Discussion}

The state of the art literature analysis in Section 2 revealed that the majority of existing studies focus on specific aspects or indicators of the triple bottom line approach, but without explicitly making a relation to the overarching aims of a 'sustainable development'. The potentials for resource efficiency through Industrie 4.0 as well as a hypothetical symbiosis of a digitalised industry with renewable energies have also not been sufficiently researched, yet. For that reason, the aim of the study was to lay the foundation for identifying possible environmental challenges and opportunities for a sustainable industrial development in the context of Industrie 4.0.

One interesting result supporting the argument is the relatively small share of participants who believe that industrial digitalisation will have an impact on their companies` sustainability strategies. This supports the impression gained in the state of the art literature analysis that sustainability initiatives and the digitalisation of production are not yet linked in the perception of industry experts. To avoid wasting sustainability potentials, this gap has to be addressed, and sustainability managers of companies should be involved as early as possible in the transition to Industrie 4.0.

Expectations for improved resource efficiency are high among the participating experts. But our results also support the need to include the resource consumption of additional technologies - in particular information and communication technologies used 
in the frame of Industrie 4.0 - when assessing possible impacts on resource efficiency. The majority of participants indeed expected a considerable increase of the role of ICT in finished products, be it through more electronics inside the products or on the user interface. This is especially important from an environmental point of view since electronic components contain critical raw materials like rare earth elements. The individualisation of products - especially from a production perspective - is expected to be a major factor for improved resource efficiency due to the avoidance of overproduction. At the same time, participants stated that the number of suppliers will increase because individual product components will be delivered much more often from specialised suppliers. One consequence of this decentralisation of production could be a higher transport volume and an increase of the related greenhouse gas emissions. This is one example of possible rebound effects which are not sufficiently dealt with in literature yet, but have to be closely monitored in sustainability science.

Although resource efficiency is an important topic in the context of Industrie 4.0, experts in our survey did not expect a considerable decrease in energy consumption. This somewhat ambiguous picture underlines the necessity of in-depth research, including thorough life-cycle assessments, to determine what the real potentials and possible rebound effects are concerning material and energy efficiency. Especially when taking into account that many non-scientific Industrie 4.0 publications promise significant energy savings.

Another important environmental aspect is the potential synergies between the energy transition and a digitalised production. More than a third of all participants in our survey anticipate that their companies will produce their own renewable energy in the future. This underpins the idea of linking the visions of energy transition with a smart industrial production, as drafted in UNIDO (2017). One idea in this regard would be to integrate smart production into smart grids, and use the flexibility of an interconnected and digitalised industrial production to synchronise energy availability and energy-intensive industrial production. Our results show that this is not an unrealistic scenario, although the adaptability of industrial production will still have its own limitations. In branches like the cement industry, for example, a synchronisation would be very challenging since the blast furnace operates at extremely high temperatures, which requires a long and very energy-intensive heating-up process. Improvements in the field of energy efficiency, the integration of renewable energy and optimised logistics can potentially lead to a reduction of greenhouse gas emissions.

Experts seem to be hesitant to enhance the level of interconnectedness with external production means which would also include suppliers, although the number of suppliers is expected to rise. This could, among other things, be explained by data security concerns that have not yet been solved. Nevertheless, will the way of how production networks are organised and connected in the future have a non-negligible influence on the environmental dimension of sustainability. This holds true not only in terms of e.g., increased needs for transport, but also regarding the ability to fully document environmental data along the whole product life-cycle in the context of an interconnected supply chain. This data could be used to ease environmental management and improve the environmental transparency of companies, e.g., in the context of sustainability reporting, compliance, or product labelling.

In the following subsection, a short scenario is presented focusing on the resource efficient production of the future. Parts of the following scenario are based on insights gained through a number of stakeholder workshops organised by the authors of this 
paper, being complemented by ideas discussed in the literature and own thoughts. Some of the thoughts, such as the increased level of product customisation have been evaluated in the course of the presented survey. This scenario is intended as a basis for further discussions and the generation of new research questions.

\subsection{A short scenario of a fictitious resource-efficient factory of the future}

In the factory of the future, products will to a large extent be manufactured according to customer specifications, which will in turn shape general expectations with respect to product customisation. Configurability will thus need to be factored into the product development process. Achieving this will require the adoption of a production model that is more responsive to the concrete parameters of customer orders, and less focused on stockpiling mass-produced goods. One consequence of this will be a significant reduction of excess in production (which will per se lower demand for material inputs) as well as warehousing requirements.

Tracking operative data in digitalised production flows provides opportunities to identify machines and processes with significantly high energy and material input requirements. In those cases where more resource-efficient alternatives are available, production could be prioritised so that those processes identified as poor performers would only be activated during capacity bottlenecks.

The use of automated planning processes will also enable manufacturers to precisely schedule with precision the running times of manufacturing machines and/or their auxiliary units, allowing machines to be activated and deactivated as required. This improved planning capacity will also help to minimise standby times, during which the energy consumption of unproductive machinery is comparatively high (Kuhrke and Rothenbücher, 2015).

One advantage of digitalising the entire production chain is that it also ensures that information about the materials contained within a given product will be available throughout its entire life-cycle. This information could potentially revolutionise conventional recycling and recovery processes as the use of unique identifiers such as RFID tags potentially enable processors to access detailed information on the composition of individual components of discarded products. Providing access to this information would facilitate the planning of appropriate recycling processes and document the proper processing of discarded products, enabling manufacturers to fulfil their legal obligations.

It should be noted, however, that many objects, including components and modules but also warehouse and transportation facilities as well as manufacturing machinery, will need to be equipped with the ICT-components necessary for digital communication. Producing these components will necessitate the consumption of additional resources, although progress in miniaturisation is continuously being made. The constant capture, processing and transmission of data could also increase electricity consumption.

\section{Conclusion and outlook}

This paper presented a short study investigating how the digitalisation of industry might influence a sustainable development with a focus on the environmental dimension. Based on a survey among German companies and research institutions as well as two interviews 
with managers from the automotive branch respectively the manufacturing industry, the first set of ideas was provided. In terms of possible environmental effects, the topics of resource efficiency and the compatibility with the energy transition could be identified as promising topics for further research. Industrie 4.0 related technologies will be applied globally, so a scientific evaluation of how this technological development affects sustainability aspects in different regions should be undertaken -as started on the examples of Germany and China in Beier et al. (2017). Additionally, another research gap could be identified as there seems to be little awareness in companies regarding possible linkages between environmental management and future technological developments. Further research should focus on how to help integrate the digitalised production in corporate sustainability management in a comprehensive way. This integrative approach would help identify and size sustainability potentials, and avoid mere problem shifts and rebound effects.

The findings of this study are limited to a certain extent because of the relatively small sample and the lack of control regarding the selection of participants. This led to a heterogeneous sample and more importantly to the results of the survey not being fully representative. Future surveys in this area should, therefore, focus on in-depth analysis of specialised samples, such as companies from only one specific sector or size to produce representative results. The findings can also not be considered completely transferable from Germany to other countries, especially regarding possible linkages to the energy transition. Nonetheless, we believe this short study is a good starting point to evaluate some sustainability potentials provided through Industrie 4.0 and helps to identify further research questions.

\section{References}

Autor, D.H. and Dorn, D. (2013) 'The growth of low-skill service jobs and the polarization of the US labor market', American Economic Review, Vol. 103, No. 5, pp.1553-1597.

Brecher, C., Herfs, W., Heyers, C., Klein, W. and Triebs, J. (2010) 'Ressourceneffizienz von Werkzeugmaschinen im Fokus der Forschung. Effizienzsteigerung durch Optimierung der Technologien zum Komponentenbetrieb', wt Werkstattstechnik online, Vol. 100, Nos. 7-8, pp.559-564.

Beier, G., Niehoff, S. and Maas, A. (2015) 'Nachhaltigkeitsaspekte von Industrie 4.0', Ökologisches Wirtschaften, Vol. 4, No. 30, pp.8, 9.

Beier, G., Niehoff, S., Ziems, T. and Xue, B. (2017) 'Sustainability aspects of a digitalized industry - a comparative study from China and Germany', International Journal of Precision Engineering and Manufacturing - Green Technology, Vol. 4, No. 2, pp.227-234.

Bornschlegl, M., Drechsel, M., Kreitlein, S., Bregulla, M. and Franke, J. (2013) 'A new approach to increasing energy efficiency by utilizing cyber-physical energy systems', Proceedings of the 11th Workshop on Intelligent Solutions in Embedded Systems, Pilsen, pp.1-6.

Bowles, J. (2014) The Computerisation of European Jobs: Who Will Win and Who Will Lose from the Impact of New Technology onto Old Areas of Employment?, Bruegel, www.bruegel.org/nc/blog/detail/article/1394-the-computerisation-of-european-jobs/ (Accessed 10 June, 2015).

Bundesministerium für Bildung und Forschung (2013) Zukunftsbild "Industrie 4.0", https://www.bmbf.de/pub/Zukunftsbild_Industrie_40.pdf (Accessed 19 February, 2016).

Derler, P., Lee, E.A. and Vincentelli, A.S. (2012) 'Modeling cyber-physical systems', Proceedings of the IEEE, Vol. 100, No. 1, pp.13-28. 
Ding, K., Jiang, P. and Zheng, M. (2017) 'Environmental and economic sustainability-aware resource service scheduling for industrial product service systems', Journal of Intelligent Manufacturing, Vol. 28, No. 6, pp.1303-1316.

Duflou, J.R., Sutherland, J.W., Dornfeld, D., Herrmann, C., Jeswiet, J. and Kara, S. (2012) 'Towards energy and resource efficient manufacturing: a processes and systems approach', CIRP Annals - Manufacturing Technology, Vol. 61, No. 2, pp.587-609.

Eurostat (2015a) Final Energy Consumption by Sector: Reference Year 2013, http://ec.europa.eu/ eurostat/tgm/table.do?tab=table\&init=1\&language $=$ en\&pcode $=$ tsdpc $320 \& p l u g i n=1 \quad$ (Accessed 15 December, 2015).

Eurostat (2015b) 'Greenhouse gas emissions by sector: Reference Year 2013, $\mathrm{http}: / /$ ec.europa.eu/eurostat/tgm/table.do?tab=table\&init=1\&language=en\&pcode $=t \operatorname{sdcc} 210 \& \mathrm{p}$ lugin=1 (Accessed 10 December, 2015).

Eurostat (2015c) National Accounts by 10 Branches - Employment Data: Reference Year 2013, http://appsso.eurostat.ec.europa.eu/nui/show.do?dataset=nama_nace10_e\&lang=en (Accessed 10 December, 2015).

Eurostat (2016) National Accounts by 10 Branches - Aggregates at Current Prices: Reference Year 2013, http://appsso.eurostat.ec.europa.eu/nui/show.do?dataset=nama_nace10_c\&lang=en (Accessed 23 February, 2016).

Federal Ministry for Economic (2015) Monitoring 2015, DIGITAL Economy.

Geissbauer, R., Schrauf, S., Koch, V. and Kuge, S. (2014) Industrie 4.0 - Chancen und Herausforderungen der vierten industriellen Revolution, PricewaterhouseCoopers AG.

Glatz, R. (2016) Digital-vernetztes Denken in der Produktion, VDMA- IMPULS-Studie.

Gossart, C. (2015) 'Rebound effects and ICT: a review of the literature', in Hilty, L.M. and Aebischer, B. (Eds.): ICT Innovations for Sustainability, Springer International Publishing, Cham, pp.435-448.

Gu, C., Leveneur, S., Estel, L. and Yassine, A. (2013) 'Modeling and optimization of material/energy flow exchanges in an eco-industrial park', Energy Procedia, Vol. 36, pp.243-252.

Herrmann, C., Schmidt, C., Kurle, D., Blume, St. and Thiede, S. (2014) 'Sustainability in manufacturing and factories of the future', International Journal of Precision Engineering and Manufacturing - Green Technology, Vol. 1, No. 4, pp.283-292.

IDG Research Services (2017) Studie Industrie 4.0 2017.

Kagermann, H., Wahlster, W. and Helbig, J. (2012) Vorläufige Umsetzungsempfehlungen für das Zukunftsprojekt Industrie 4.0: Deutschlands Zukunft als Produktionsstandort sichern, Forschungsunion Wirtschaft - Wissenschaft.

Kagermann, H., Wahlster, W. and Helbig, J. (2013) Securing the Future of German Manufacturing Industry. Recommendations for Implementing the Strategic Initiative INDUSTRIE 4.0, Final Report of the Industrie 4.0 Working Group, acatech - Deutsche Akademie der Technikwissenschaften e. V.

Kang, H.S., Lee, J.Y., Choi, S., Kim, H., Park, J.H., Son, J.Y., Kim, B.H. and Noh, S.D. (2016) 'Smart manufacturing: past research, present findings, and future directions', International Journal of Precision Engineering and Manufacturing - Green Technology, Vol. 3, No. 1, pp.111-128.

Keeso, A. (2014) Big Data and Environmental Sustainability: A Conversation Starter, Smith School Working Paper Series.

Krückhans, B. and Meier, H. (2013) 'Industrie 4.0 - Handlungsfelder der Digitalen Fabrik zur Optimierung der Ressourceneffizienz in der Produktion', in Dangelmaier, W., Laroque, C. and Klaas, A. (Eds.): Simulation in Produktion und Logistik: Entscheidungsunterstützung von der Planung bis zur Steuerung, HNI - Verlagsschriftenreihe, Paderborn, pp.31-40. 
Kuhrke, B. and Rothenbücher, S. (2015) Vermeiden von Stand-By-Zeiten verbessert die Energieeffizienz von Maschinen. Maschinenmarkt - Das Industrieportal, http://www. maschinenmarkt.vogel.de/themenkanaele/produktion/zerspanung/articles/137254/index2.html (Accessed 9 July, 2015).

Larreina, J., Gontarz, A. and Giannoulis, C. (2013) 'Smart manufacturing execution system (SMES): the possibilities to evaluate the sustainability of production process', The 11th Global Conference on Sustainable Manufacturing, Berlin, pp.467-472.

Lee, J., Bagheri, B. and Kao, H.-A. (2015) 'A cyber-physical systems architecture for Industry 4.0based manufacturing systems', Manufacturing Letters, Vol. 3, pp.18-23.

OECD (2014) OECD Digital Economy Papers, Viewed 15 August, 2016.

Rogers, E.A., Elliott, R.N., Kwatra, S., Trombley, D. and Nadadur, V. (2013) Intelligent Efficiency: Opportunities, Barriers, and Solutions, American Council for an Energy-Efficient Economy (ACEEE) (Accessed 1 June, 2016).

Rohn, H., Pastewski, N., Lettenmeier, M., Wiesen, K. and Bienge, K. (2014) 'Resource efficiency potential of selected technologies, products and strategies', The Science of the Total Environment, Vols. 473-474, pp. 32-35.

Schmidt, R., Möhring, M., Härting, R-C., Reichstein, C. and Neumaier, P. (2015) 'Industry 4.0 potentials for creating smart products: empirical research results', Business Information Systems, Nr. 208, pp.16-27.

Statistisches Bundesamt (2014) Nachhaltige Entwicklung in Deutschland - Indikatorenbericht 2014. Viewed 29 January, 2016.

The Federal Government (2017) German Sustainable Development Strategy, https://www. bundesregierung.de/Content/DE/_Anlagen/2017/02/2017-02-27-nachhaltigkeit-neuauflageengl.pdf? blob=publicationFile\&v=1 (Accessed 20 August, 2017).

UNIDO (2017) 'Accelerating clean energy through Industry 4.0: manufacturing the next revolution', in Nagasawa, T., Pillay, C., Beier, G., Fritzsche, K., Pougel, F., Takama, T., The, K. and Bobashev, I. (Eds.): A Report of the United Nations Industrial Development Organization, Vienna, Austria.

\section{Note}

${ }^{1}$ Find the complete questionnaire on htp://survey.iass-potsdam.de/index.php/953428?lang=de 